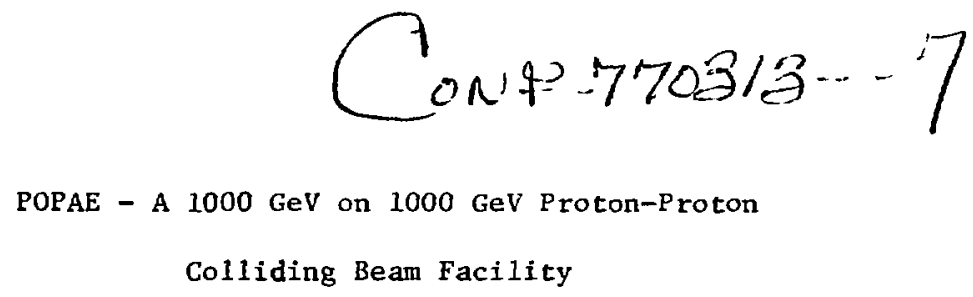

D. Ayres, E. Berger, Y. Cho, T. Collins, E. Crosbie, M. Derrick, R. Diebold, D. Edwards, M. Foss, L. Genens, L. Hyman, D. Johnson, E. Malamud, F. Mills, L. Mo, J. Moenich, S. Ohnuma, J. Purcell, C. Quigg, L. Ratner, A. Ruggiero, R. Singer, R. Smith, S. Snowdon, L. Teng, L. Turner and C. Ward

1977 Particle Accelerator Conference Chicago, Illinois

March 16-18, 1977
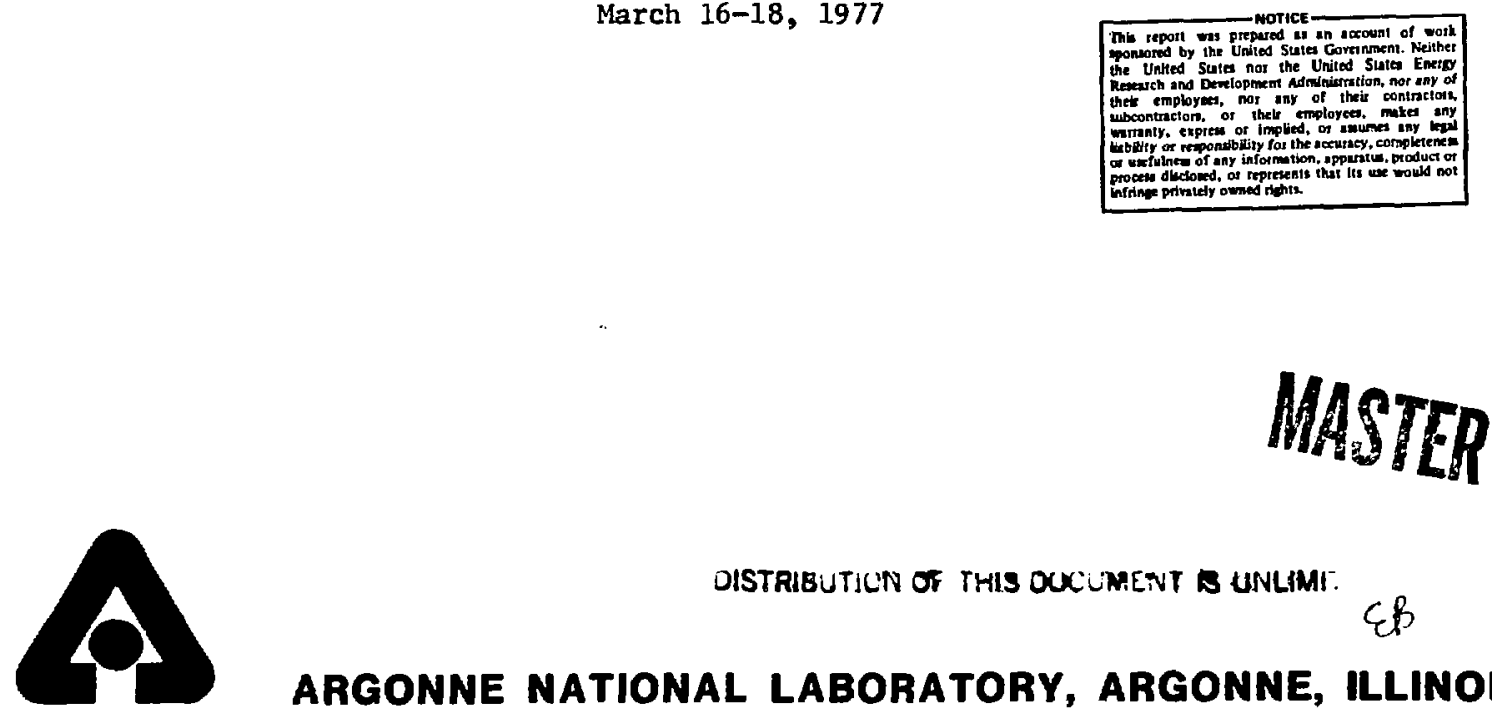

DISTRIBUTILN OF THIS OUCLMENT B UNLIMI.

$\varepsilon B$

ARGONNE NATIONAL LABORATORY, ARGONNE, ILLINOIS

operated under contract W-31-109-Eng-38 for the U. S. ENERGY RESEARCH AND DEVELOPMENT ADMINISTRATION 

COLLIDING BEAM FACILITY"

D. Ayres, E. Berger, Y. Cho, T. Collins, E. Crosbie, M. Derrick, R. Diebold,

D. Fdwards, M. Foss, L. Genens, L. Hyman, D. Johnson, E. Malamud, F. Mills,

L. Mo, J. Moenich, S. Ohnuma, J. Purcell, C. Quigg, L. Ratner, A. Ruggiero.

R. Singer, R. Smith, S, Snowdon, L. Teng, L. Turner and C. Ward

\section{The Argonne-Fermilab POPAF, Collaboration}

Argonne National Laboratory, Argonne, Illinois 60439, and

Fermi National Accelerator Laboratory, Batavia, Illinois 60510

\section{Summary}

A proposal has been developed for the construction of a $1000 \mathrm{GeV}$ on $1000 \mathrm{Gr} V \mathrm{~V}$ colliding beam facility at Fermi National Aceclerator linberatery. To achiceve: the same 2000-cic $V$ center-of-mass cnergy with a fixed target accelrerator would recquirs: a beam of more than $2 \times 10^{6}$ (ic. V. The lotal circurnference of the facility is $5520 \mathrm{~m}$, including six straight sections, each $200 \mathrm{~m}$ long. Injection from the fermilab main ring or Energy Saver/Doubler (ES/ID) will be at the energy desired for interactions, thus avoiding the uncertainty, complication, and cost of accelerating very intense beams in the storage rings themselves. Each ring will require 570 superconducting dipole magnets, each $6.2 \mathrm{~m}$ long; the field required at $1000 \mathrm{GeV}$ is $60 \mathrm{kG}$. For $a$ proton current of $5 \mathrm{~A}$ in each ring at $1000 \mathrm{GeV}$. the high-luminosity ingertion is designed to give $\Sigma=4 \times 10^{33} \mathrm{~cm}^{-2} \mathrm{sec}^{-1}$.

The proposal ${ }^{1}$ was developed during an intensive study from November 1975 to April 1976. This study drew not only on the experience of the C.F.RN ISR ${ }^{2}$ and previous Fermilab designs, "but also on studies of high energy storage rings made at Iruokhaven National Laboratory (Isabelle) ${ }^{4}$ and at CERN (LSR). 5

\section{Reason for Colliding Beams}

The great atvantage of colliding boams is the very large energy available to produce massive particles or to explore new types of interactions and forces. At fixed target acceleratora the center-of-mass energy $W$ increases only as the square root of the laboratory energy $E, W_{\sim} \sqrt{1.88 E}$, where both $W$ and $E$ are in units of GeV. For colliding beams the situation is much more favorable, $W=2 E$, where $E$ is the laboratory energy of each of the protons in a head-on collision.

At present, the world's only proton-proton colliding beam facility is at Cl:RN, the- Intersecting storigh: lings (ISR). " This facility gave all anorness increase in ugeful energy over that previously available at CERN, up to the equivalent of a $2000-\mathrm{GeV}$ fixed-target accelerator. However, this energy has eince been approached by Fermilab and the CERN SPS which are now running routinely at $400 \mathrm{GeV}$ and by the ES/D which will achieve $1000 \mathrm{GeV}$. For further energy increases, however, colliding beams quickly outstrip the useful energy of fixed target machines, even those that might conceivably be built as part of a World Collaboration. This is illustrated in Fig. 1.

Work supported by the U.S. Encrgy Research and Development Administration.
The factor of 1000 increase in equivalent fixedtarget machine energy of POPAE over that of the 1SR will almost certainly lead to new and interesting phenomena. If we reflect back on the previous factor of 1000. from 2 to 2000 Ciev, we finel that our whesle colstlook on clementary particles hat bien changred ol rillittically by the phenomena found in this enr.rgy ringe. $\mathrm{Al}$ l'Oreft, a further increase of at leatst $50 \%$ is porijer (c.d

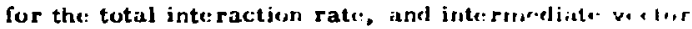
bosons, which mediato the weak interactiests, a $r . \ldots \%$ pected to be produced at the ratc of about $10 / \mathrm{sec}$. It seems inevitable, however, that these and other $x: x-$ pectations will pale beside the phenomena actually discovered.

\section{Storage Ring Design}

The proposed Iocation for POPAE on the Fermilab site is shown in Fig. 2, and results in nearly straight injection lines to the storage rings. These lines will consist mainly of buried vacuum pipe with quad rupoll: doublets every 150 meters for focusing, anel will bs: relatively inexpensive both to build and to ope rats. (one of the se: lines will originate at the " $Q$ stub" and the. other from a new extraction point at the It straight section.

Some important design parametrers at re surninarined in Table 1. The two rings will be housed in a common tunnel and rach will have six 720-rm:tur lrong curved sections, separated by 21$)(1)-m i t e$ er long st raight sections where the beams are focused and crosis ons.

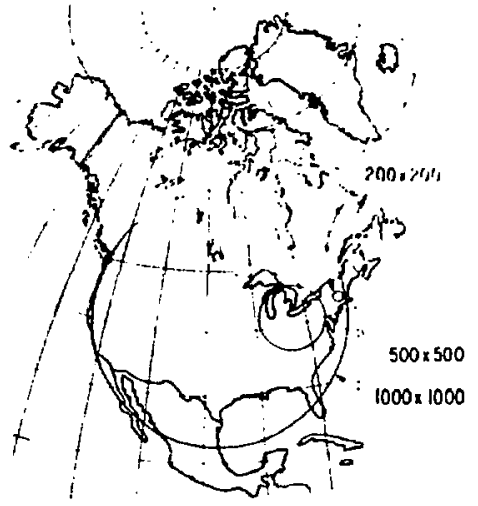

Fig. 1. Size of fixed-target accelerators (with $40 \mathrm{kG}$ dipoles) to achieve the same center-of-mass energy as proton-proton storage rings of the energies indicated (GeV). 


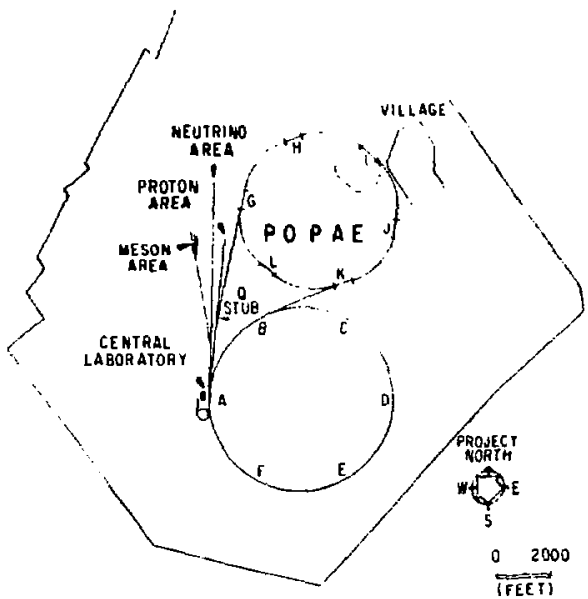

Fig. 2. Location of POPAE on the Fermilab site. The dashed ring shows a possible future location of a 20-GeV electron storage ring for ep ccllivions.

Table I. Bașic POPAE parameters.

\section{ENERGY}

Maximum energy in each sing

Equivalent fixed-target energy

\section{GeV}

2100 TeV

LATTICE

Circumference

tagertion lenulh

Coll lingth

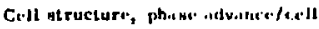

Tune (irpicis) $\nu_{h}, v_{4}$

Trineitican anerky $\left\langle Y_{1,}\right\rangle$

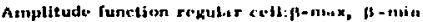

Maximum disper $r i, n n, \eta$

MAGNET SYSTFM

Number of latice dipoles/ring

Bending fieid at $1000 \mathrm{CuV}$

Dipole length

Stored ene ray pur dipole id 6,1) KG

Nunber of lattice kjual rupust:s/ rimp

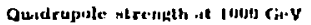

Quidrupula. bougth

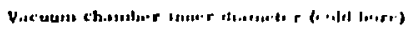

REFIIGFRATION SYSTYM

Reliquificstion of winfm has

Refrigeration at $4.5^{\circ} \mathrm{K}$

Powtr requirement of coniprensore

Total liquid helium inventury

INJE,CTION

Injected eneray/central aturake rink enerky

Number of jurctons per ES/D pul He

Emittance of ES/D heam at 1000 GoV: $h$. A

Longitudinal phane epace per bunch at $1000 \mathrm{GLV}$

POPAE current/rint

Number protemn/rint;

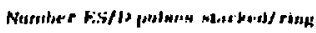

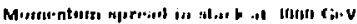

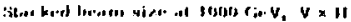

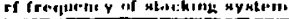

another. Fach 720-metor long sextant is composed of

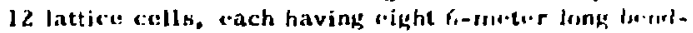

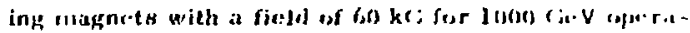
tion. 'The lattice and insertiens are diteushed in M, r. detail in another paper ${ }^{6}$ at this conference: sornc of thr. performance parameters are summarized in Table II.

Injection into the storage rings will be handled in a manner eimilas to that used at the ISR, making use of $r f$ stacking in momentum space. The filling time will range from a few minutes at low energies to about one hour at $1000 \mathrm{GeV}$. Each ring can store high beam currents at energies between $100 \mathrm{GeV}$ and $1000 \mathrm{GeV}$, and uncqual-energy operation is possible. There is no firm low-energy limit and although the attainable luminosity falls with decreasing energy, some experiments should be possible even below $100 \mathrm{GeV}$.

The design luminosity, $\mathcal{X}=4 \times 10^{33} \mathrm{~cm}^{-2} \mathrm{sec}^{-1}$. is two orders of magnitude higher than the values obtained at the 15R. This increase is possible even with a lower proticn current because of the high energy; the beams are smaller in size aid a smaller crossing angle can be used without the beam-beam tune shift becoming important. There appears to be no hard limit on the stored proton current, and it may eventually be possible to store more than the design current of 5A, possibly yielding $\mathcal{L}>10^{34} \mathrm{~cm}^{-2}$ sec $^{-1}$.

\section{Magnets and Vacuum}

There are several clear advantages to using superconducting magnets for high energy storage rings. The power saving even for magnets operating at $20 \mathrm{kG}$ amounts to hundred $s$ of megawatts, and the length of expenaive underground tunnel can be: reduced by a factor of two or three due to the higher ficlde obtrinible. The design field of $60 \mathrm{kG}$ at $1000 \mathrm{GcV}$ is sornewhat higher than the 40 to $45 \mathrm{kG}$ design of present accelerator projects, all of which were started several years ago. With the steady improvements in technology. $60 \mathrm{kG}$ superconducting de dipoles now seem quite feasible, and this field is a worthy goal for the next step in dipole technology. For POPAE, this high ficld will result both in savings and in reduced sensitivity to various instabilities.

Since protons arc: stored at a fixed energy, and the high-current beam is not accelcratcd, siveral of the design critcria commonly imposed an pulecd nugnrts can be: relaxed. Pectangular monolithic wirs es 1 ilsls: can be utilized insteal of braid, thus gaving the:

Table II. Typical performance parameters.

\begin{tabular}{|c|c|c|c|c|c|c|}
\hline \multirow{3}{*}{$\begin{array}{l}\text { Type of Instrtiun } \\
\text { Eneryy (Corv) }\end{array}$} & \multirow{3}{*}{$\begin{array}{l}\text { Injection - } \\
\text { Crmanios } \\
\end{array}$} & \multirow{3}{*}{$\begin{array}{l}\text { Hiph of } \\
\text { joun }\end{array}$} & \multicolumn{3}{|c|}{ Low $B_{n}^{\pi}$} & \multirow{3}{*}{$\begin{array}{l}\text { Pliph } \\
\text { l.wminnisgt } \\
\text { L100 }\end{array}$} \\
\hline & & & \multicolumn{2}{|c|}{ Latrie Angles } & \multirow{2}{*}{$\begin{array}{l}\text { Frmisls } \\
\text { tripsle } \\
\text { 1000 }\end{array}$} & \\
\hline & & & 100 & 1000 & & \\
\hline Luminonity $\left(10^{33} / \mathrm{cm}^{2} / \mathrm{sec}\right.$ & $0.0+1$ & 0.0217 & 0.12 & 0.26 & 2.8 & 4,5 \\
\hline Tune shift $\left(10^{-3}\right)$ & 3 & + & 2 & 0.4 & 7 & 1 \\
\hline Crusting angte (mrad) & II & 11 & 11 & $\|$ & 1 & $\mathbf{I}$ \\
\hline Fret upiee $(m)$ & $+2 n$ & \pm 45 & 115 & 145 & $t t$ & th \\
\hline 'Itill-reit litent & 0,2 & 10.1 & 1.. 2 & 1.1 & I. " & ". 1 \\
\hline$=(n \cdot 1$ & bs! & 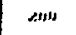 & '. & $A_{0} \cdot 4$ & $\sim \cdot$ & I \\
\hline$I_{l i}^{*}(1+1)$ & भI & 12.4 & $1:$. & $1: 4$ & $1::$ & $:$ \\
\hline Fntion $(s+n)$ & strits & rints & $m s$ & $4 n$ & ner & $1+\ldots 14$ \\
\hline
\end{tabular}


expense of braiding as well as improving the coil packjns fraction. A thick metal bore tube can be employed for mechanical rigidity, without concern for eddy currents which degrade the field quality of a pulsed magnot. A rlc magnet also has less stringent requirements un the insulation betwien superconducting elements, and does not rerpuire field corrictions that depend on the rate at which the magnet is ramped.

Thr magnct design adogted for lPOHAE ja describud in cletail alsewher.. 5 It is simbilar to a f,o-kr; dipole magnet built and operated at Saclay, with rectangular coils wound with rectangular conductor. $\$$ The magnet design incorporates both cold bore and cold iron, as well as liquid-nitrogen-cooled heat shields in the magnet cryostat. The result is a very low heat load on the liquid helium system and a substantial saving on refrigerator costs and power consumption.9

The $6-\mathrm{cm}$ vacuum tube bore is substantially smaller than the $8-\mathrm{cm}$ bure proposed for Isabelle. The choice of bore diameter is influenced by many aspects of over-all design such as machine instabilitics, vacuum, beam size, cte. In general, a bigger bore helps with various potential problems that may or may not be critical, but it does cost money. POPAE has the option of using a smalle $r$ bore, since there is no need to store and bunch the full beam intensity at low energy. Beam instabilitie $B$ become more important as the beam current increases and, for a given cost, the smaller bore size of POPAE essentially trades luminosity for increased energy. The 5-ampere beam current needed to reach design luminosity will place considerably less stringent requirements on the entire system than does the 40 -ampere current achieved at the ISR.

The vacuum will be primarily a cold-bore system, with warm bore only in the straight sections, a ratural choice for a ring of superconducting magnets. With high-vacuum preparation of materials, a vacuum of about $10^{-11}$ Torr will be obtained in the warm-bore sections, while better than $10^{-13}$ Torr is expected from the cold-bore regions. With high pumping speed of the bore tube at liquid-helium temperature and the relatively low beam current, it should not be difficult to avoid the pressure bump problem seen at the ISR. The vacuum design is discussed in detail in another paper ${ }^{10}$ presented to this conference.

\section{Cost Estimate}

Table III summarizes the results of a detailed estimate of the cost of constructing and bringing into operation the POPAE colliding beam facility. The construction of this facility at Fermilab takes advantage of the substantial national investment in the facilities of the Laboratory.

For planning and costing purposes, a model set of initial cxperiments was developed. With this ohysics program as a guide, experimental halls were designed and included in the estimate for the conventional facilities construction. The cost estimate for the POPAE superconducting mas sets made use of current conceptual designs and recent experience with superconducting magnet fabrication at Argonne and at Fermilab.
Table III. POPAE cost estimate (in millions of 1 y 10 dollars).

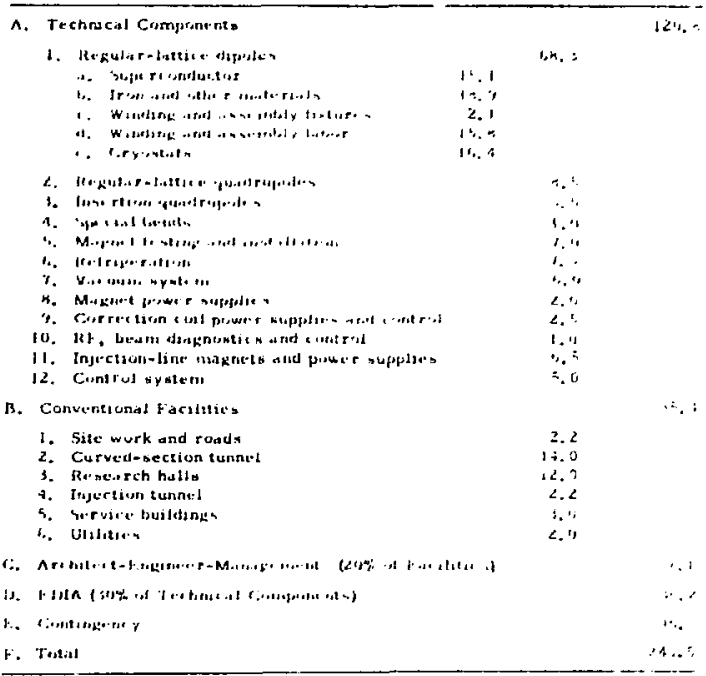

The cost of the project was estimated to be $\$ 245 \mathrm{M}$ in 1976 dollars.

Since economic constraints may force a reduction in scope, an estimate was also made of the saving which could be realized by lowe ring the peak energy of POPAE. The 1000-GeV ring geometry is retained (leaving open the possibility of eventual operation at higher energy/ and $30 \mathrm{kG}$, ES/D-type superconducting dipoles are used. Since the magnets are such a large part of the cost, the savings are substantial, and the cost of a 500-GeV on 500-GeV facility is estimated to be $\$ 155 \mathrm{M}$ in 1976 dollars.

\section{References}

1. Copies of the POPAE Proposal are available upon request from the Publications Office, Fermilab.

2. For a recent description of ISR operating experience see W. Schnell, IEEE Trans. on Nucl. Sci. NS-22, 1358 (1975).

3. T. L. Collins et al., IEEE Trans, on Nucl. Sici. NS-22. 1411 (1975).

4. "A Proposal for Construction of a l'rotun-f'rutern Storage Accelerator Facility LSARF,LLF.." BNL-18891 (1974) and 13NL-20161 (1975), unpublished.

5. B. Autin et al., CERN/ISR-LTD/75-46 (1975), unpublished.

6. Y. Cho et al. "Lattice Insertions for POPAE", this conference.

7. J. Bywater et al., IEEE Trans, on Magnetics, MAG-13, 82 (1977).

8. H. Deportes, Fifth Int. Conf. on Magnet Tech., Frascati, p. 502 (1975).

9. P. Vander Arend served as cryogenic consultant.

10. Y. Cho et al., "A Cold-Bore Vacuum System Design for POPAE", this conference. 